\title{
General Psychiatry Isolation and mental health: challenges and experiences from China
}

\author{
Xing Wang, Jun Chen (D)
}

To cite: Wang X, Chen J. Isolation and mental health: challenges and experiences from China. General Psychiatry 2021;34:e100565. doi:10.1136/ gpsych-2021-100565

Received 07 May 2021 Accepted 15 June 2021

Check for updates

(C) Author(s) (or their employer(s)) 2021. Re-use permitted under CC BY-NC. No commercial re-use. See rights and permissions. Published by BMJ.

Clinical Research Center, Shanghai Mental Health Center, Shanghai Jiao Tong University School of Medicine, Shanghai, People's Republic of China

Correspondence to

Dr Jun Chen;

doctorcj2010@gmail.com
Isolation is a common phenomenon during the COVID-19 global pandemic, impacting people's physical and mental health worldwide. ${ }^{12}$ Based on a rapid systematic review, Loades et al concluded that people were more likely to suffer from depression or anxiety during and after enforced isolation. Taquet $e t a t^{4}$ followed up 62 354 patients with COVID-19 in the USA and found an increased incidence of mood and anxiety disorders in this population. However, more worrying is the long-term influence on all-cause mortality due to social isolation, loneliness or living alone. ${ }^{5}$ Even more, current evidence suggests that mental health issues may arise after the peak of the pandemic, with increased prevalence among vulnerable populations and people with risk factors. ${ }^{6}$ Vulnerable populations include children and adolescents, the elderly, unemployed and homeless persons, COVID-19 survivors, healthcare workers, people with pre-existing psychiatric disorders, community workers, pregnant women, people with disabilities and chronic diseases, migrants, refugees, and lesbian, gay, bisexual, transgender and queer community members, as well as racial and ethnic minorities. Risk factors include death of either the parents, caregivers or loved ones, misinformation, loss of peer support due to closure of school or workplace, academic loss, medical comorbidities, uncertainties, stigma, prolonged isolation, social rejection, work stress, burnout, being in direct contact with active cases and facing economic burden.

However, there may be some common misapprehension about the concept of 'isolation'. Social isolation is a state of complete or nearcomplete lack of contact between an individual and the society. In contrast, loneliness is the feeling of being alone and reflects a temporary and involuntary lack of contact with others. These two words sound similar but may result in different endings. For example, patients with COVID-19 who are in quarantine may feel lonely but may not meet the definition of social isolation. It is why the WHO suggested using the term 'physical distancing' instead of 'social distancing', because it is a physical separation that prevents transmission. ${ }^{7}$ At the same time, people can remain socially connected by meeting outdoors or via technology. To sum up, it is clear that we need physical distancing during the COVID-19 global pandemic but need to prevent social isolation.

Unfortunately, there are massive challenges to preventing social isolation. First, the vulnerable population of social isolation may be wildly distributed. Second, there is no standard tool for screening and defining social isolation. Third is the discrimination against patients with COVID-19 and their family members. Last but not the least are the continuous worldwide pandemic surges and the variants of COVID-19 that may aggravate social isolation. Results from a review showed that majority of participants who identified as 'socially isolated' were self-referred or self-identified. ${ }^{8}$ Effective interventions to reduce social isolation that are compatible with the circumstances of the COVID-19 pandemic are minimal. A newly published rapid systematic review showed that many effective interventions involved cognitive or educational components, or facilitated communication between peers. Unfortunately, among all the identified 58 studies, none was conducted during the COVID-19 pandemic. ${ }^{9}$

Although the pandemic in China is currently well controlled, the direct and indirect influence of COVID-19 will continue for an extended period. The psychological impact may differ in different populations and periods during or after the pandemic, but all of these psychological factors may directly or indirectly cause social isolation. For example, patients with COVID-19 may worry about stigma and discrimination when they return to communities. They may even continue to worry about their physical and mental condition due to the potential long-term side effects of the virus. Front-line medical staff and community workers may develop occupational burnout or post-traumatic stress disorders. The public may worry about new waves of the pandemic, their jobs, business and economic 
income, and even vaccine safety. These impacts prove the importance of mental health intervention and social isolation prevention, as well as setting up a mental health service system during the whole course of the COVID-19 management. ${ }^{10}$

There are some publications in China that share experiences on how to avoid social isolation during the COVID-19 pandemic. During the early stage of the pandemic, psychiatrists and psychologists should be actively involved in the treatment of COVID-19 since a considerable proportion of patients with COVID-19 experience mental health issues. ${ }^{11}$ Multidisciplinary teams (MDTs) should include psychiatric experts to provide consultation and liaison psychiatry. MDTs should also provide inperson group counselling and individual psychotherapy for medical workers. ${ }^{10}$ Quarantine is a high-risk period for addictive behaviours to become problematic, especially for those with pre-existing substance abuse/dependence and addictive behaviours. ${ }^{12}$ During the pandemic, internet-based screening and psychological interventions are valuable. ${ }^{13}$ Among all the significant challenges to avoiding social isolation, stigma is the most critical issue to be solved. Chinese professionals advocated designing an effective anti-stigma programme to prevent misinterpretation and spread encouraging, positive and supportive messages. ${ }^{14}$ Family members, friends, colleagues and social support are crucial to preventing social isolation. And of course, social media allows people to communicate without time and space limitations. After the pandemic, public education and longterm follow-up programmes will be effective ways to prevent social isolation.

In China, psychiatric experts have been making contributions to public education, guidelines, regulations, expert consensus and training on these topics. ${ }^{15}$ However, future high-quality randomised controlled trials on social isolation are urgently needed.

Contributors XW drafted the manuscript and JC conceptualised and finalised the paper.

Funding This was funded by the National Natural Science Foundation of China (81761128032), Clinical Research Plan of Shanghai Hospital Development Center (SHDC12020126), Sanming Project of Medicine in Shenzhen (SZSM201612006), and Key Area Research and Development Program of Guangdong Province (2018B030334001).

Competing interests None declared.

Patient consent for publication Not required.
Provenance and peer review Commissioned; externally peer reviewed.

Open access This is an open access article distributed in accordance with the Creative Commons Attribution Non Commercial (CC BY-NC 4.0) license, which permits others to distribute, remix, adapt, build upon this work non-commercially, and license their derivative works on different terms, provided the original work is properly cited, appropriate credit is given, any changes made indicated, and the use is non-commercial. See: http://creativecommons.org/licenses/by-nc/4.0/.

ORCID iD

Jun Chen http://orcid.org/0000-0002-3837-2761

\section{REFERENCES}

1 Wu B. Social isolation and loneliness among older adults in the context of COVID-19: a global challenge. Glob Health Res Policy 2020;5:27.

2 Goodwin R, Hou WK, Sun S, et al. Quarantine, distress and interpersonal relationships during COVID-19. Gen Psychiatr 2020;33:e100385.

3 Loades ME, Chatburn E, Higson-Sweeney N, et al. Rapid systematic review: the impact of social isolation and loneliness on the mental health of children and adolescents in the context of COVID-19. J Am Acad Child Adolesc Psychiatry 2020;59:1218-39.

4 Taquet M, Luciano S, Geddes JR, et al. Bidirectional associations between COVID-19 and psychiatric disorder: retrospective cohort studies of 62354 COVID-19 cases in the USA. Lancet Psychiatry 2021;8:130-40.

5 Holt-Lunstad J, Smith TB, Baker M, et al. Loneliness and social isolation as risk factors for mortality: a meta-analytic review. Perspect Psychol Sci 2015;10:227-37.

6 Vadivel R, Shoib S, El Halabi S, et al. Mental health in the postCOVID-19 era: challenges and the way forward. Gen Psychiatr 2021;34:e100424.

7 Wasserman D, van der Gaag R, Wise J. The term "physical distancing" is recommended rather than "social distancing" during the COVID-19 pandemic for reducing feelings of rejection among people with mental health problems. Eur Psychiatry 2020;63:e52.

8 Ige J, Gibbons L, Bray I, et al. Methods of identifying and recruiting older people at risk of social isolation and loneliness: a mixed methods review. BMC Med Res Methodol 2019;19:181.

9 Williams CYK, Townson AT, Kapur M, et al. Interventions to reduce social isolation and loneliness during COVID-19 physical distancing measures: a rapid systematic review. PLoS One 2021;16:e0247139.

10 Yang T, Chen J, Lam RW, et al. Mental health service challenges during the early stage of the COVID-19 pandemic: experience and best practices from China. Can J Psychiatry 2020:706743720972252.

11 Yue L, Wang J, Ju M, et al. How psychiatrists coordinate treatment for COVID-19: a retrospective study and experience from China. Gen Psychiatr 2020;33:e100272.

$12 \mathrm{Du}$ J, Fan N, Zhao M, et al. Expert consensus on the prevention and treatment of substance use and addictive behaviourrelated disorders during the COVID-19 pandemic. Gen Psychiatr 2020;33:e100252.

13 Peng D, Wang Z, Xu Y. Challenges and opportunities in mental health services during the COVID-19 pandemic. Gen Psychiatr 2020;33:e100275.

14 Lin T-Y, Sung C-A, Shaw SW. The application of clinical ultrasound in fetal therapy. J Med Ultrasound 2021;29:1-2.

15 Duan L, Zhu G. Psychological interventions for people affected by the COVID-19 epidemic. Lancet Psychiatry 2020;7:300-2.

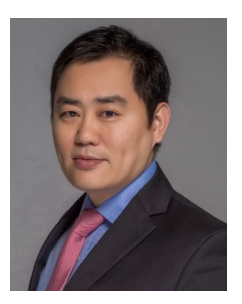

Educated in China and the US, Dr. Jun Chen received an M.D./Ph.D. degree with Prof. Yiru Fang in psychiatry at Shanghai Jiao Tong University School of Medicine in 2009. He has worked at Shanghai Mental Health Center since 2001, and is the current director of the Clinical Research Center. In addition, he is serving as a Board Member (Asia) for the International Society for Bipolar Disorders (ISBD), is a Distinguished Fellow for the Pacific Rim College of Psychiatrists (PRCP), is Vice Chairman for the Youth Committee of the Chinese Society of Psychiatry (CSP), and a Committee Member for the Chinese Psychiatrist Association (CPA). His main research interests include the phenomenon and treatment of bipolar disorder and treatmentresistant depression, using research methods including clinical trials, cognitive function measurements and neuroimaging. 